\title{
A multivariable prediction model for recovery patterns and time course of symptoms improvement in hemifacial spasm following microvascular decompression
}

\author{
Ahmed Al Menabbawy ${ }^{1,2} \cdot$ Ehab El Refaee ${ }^{1,2} \cdot$ Reem Elwy $^{2} \cdot$ Amany A. Salem $^{3} \cdot$ Sebastian Lehmann ${ }^{1}$. \\ Marcus Vollmer ${ }^{4} \cdot$ Marc Matthes $^{1} \cdot$ Steffen Fleck ${ }^{1} \cdot$ Jörg Baldauf $^{1} \cdot$ Henry W. S. Schroeder $^{1}$
}

Received: 25 November 2021 / Accepted: 12 January 2022 / Published online: 1 February 2022

(c) The Author(s) 2022

\begin{abstract}
Background Microvascular decompression (MVD) success rates exceed 90\% in hemifacial spasm (HFS). However, postoperative recovery patterns and durations are variable.

Objective We aim to study factors that might influence the postoperative patterns and duration needed until final recovery. Method Only patients following de-novo MVD with a minimum follow-up of 6 months were included. Overall trend of recovery was modeled. Patients were grouped according to recognizable clinical recovery patterns. Uni- and multivariable analyses were used to identify the factors affecting allocation to the identified patterns and time needed to final recovery. Results A total of 323 (92.6\%) patients had $>90 \%$ symptom improvement, and $269(77.1 \%)$ patients had complete resolution at the last follow-up. The overall trend of recovery showed steep remission within the first 6 months, followed by relapse peaking around 8 months with a second remission $\sim 16$ months. Five main recovery patterns were identified.

Pattern analysis showed that evident proximal indentation of the facial nerve at root exit zone (REZ), males and facial palsy are associated with earlier recovery at multivariable and univariable levels. anterior inferior cerebellar artery (AICA), AICA/ vertebral artery compressions and shorter disease durations are related to immediate resolution of the symptoms only on the univariable level. Time analysis showed that proximal indentation (vs. distal indentation), males and facial palsy witnessed significantly earlier recoveries.

Conclusion Our main finding is that in contrast to peripheral indentation, proximal indentation of the facial nerve at REZ is associated with earlier recovery. Postoperative facial palsy and AICA compressions are associated with earlier recoveries. We recommend a minimum of 1 year before evaluating the final outcome of MVD for HFS.
\end{abstract}

Keywords Microvascular decompression $\cdot$ Hemifacial spasm $\cdot$ Delayed recovery $\cdot$ Time course of recovery

This article is part of the Topical Collection on Functional Neurosurgery - Other

Ahmed Al Menabbawy

ahmed.almenabbawy@med.uni-greifswald.de;

a.menabbawy@gmail.com

1 Department of Neurosurgery, University Medicine Greifswald, Greifswald, Germany

2 Department of Neurosurgery, Kasr Alainy School of Medicine, Cairo University, Cairo, Egypt

3 Department of Public Health, Kasr Alainy School of Medicine, Cairo University, Cairo, Egypt

4 Institute of Bioinformatics, University Medicine Greifswald, Greifswald, Germany

\section{Introduction}

Hemifacial spasm (HFS) is a condition affecting the facial nerve usually causing unilateral intermittent and involuntary contractions of facial muscles $[2,7,9,33]$. This has been attributed to mostly arterial vascular compressions at the root exit zone (REZ) of the facial nerve, increasing its excitability and manifesting as the clinically known facial spasms or contractions that negatively influence the quality of life of these patients.[19, 23, 35]. The exact mechanism of hyperexcitability is still unknown. However, two theories, the central and peripheral theories, have been generally accepted [29, 32]. Microvascular decompression (MVD) is considered an effective curative treatment modality for patients with primary HFS. [7, 33, 36] However, the postoperative patterns 
of improvement and the time needed for final recovery vary widely among different patients. Furthermore, many factors might influence such patterns or courses of recovery [27, 36]. We aim to develop a multivariable prediction model for the factors affecting the time needed for final symptom resolution and recovery patterns.

\section{Methods}

\section{Dataset}

Patients written consents were obtained preoperatively for using the data for research purposes. Following the approval of our local ethical committee, we retrospectively reviewed our prospectively maintained database/registry of prospectively collected cases of HFS who underwent MVD between $01 / 2002$ and $10 / 2019$. We included only patients that were operated for the first time in our neurosurgical department of the University hospital of University Medicine Greifswald. This study was designed and implemented in accordance with "Transparent reporting of a multivariable prediction model for individual prognosis or diagnosis" (TRIPOD) guidelines statement [8].

We extracted data on patient demographics, preoperative symptom duration, side, etiology of the compressing vessel(s), type of surgical decompression performed (Interposition with shredded Teflon vs. Transposition with sling retraction), intraoperative evident indentation/grooving of the facial nerve (either "proximal" at the pontomedullary sulcus or "distal" around $5 \mathrm{~mm}$ distal to the sulcus just around the beginning of the cisternal part of the nerve (Figs. 1 and 2)).

Furthermore, postoperative development of delayed facial palsy, postoperative adjuvant Botox injections and follow-up duration were noted. We assessed postoperative outcome clinically based on patient reported symptom severity as a percentage of preoperative symptoms at each follow-up where the preoperative condition was considered $100 \%$ symptom severity. Exclusion criteria were cases with $<6$-month follow-up or non-arterial compression. In patients with more than one surgical procedure for HFS, only data regarding the first operation were included.

\section{Outcomes and predictors}

\section{Pattern analysis}

Firstly, the overall general recovery pattern of all patients was studied (as percentage of residual symptoms). Five different common clinical patterns of recovery were identified. Finally, we analyzed factors predicting the allocation of patients to each of the identified groups of remission patterns.

\section{Time analysis}

Our secondary outcome was the final $100 \%$ postoperative resolution of the spasms for every individual patient disregarding the pattern of recovery.
Fig. 1 Illustration of different arterial compressions at the root exit zone (REZ) causing proximal indentation/grooving at the brainstem $(*)$ or distal indentation/grooving (arrowhead) just before starting the cisternal part. Facial nerve myelinated fibers shown from proximal to distal with transitional zone between central and peripheral myelin

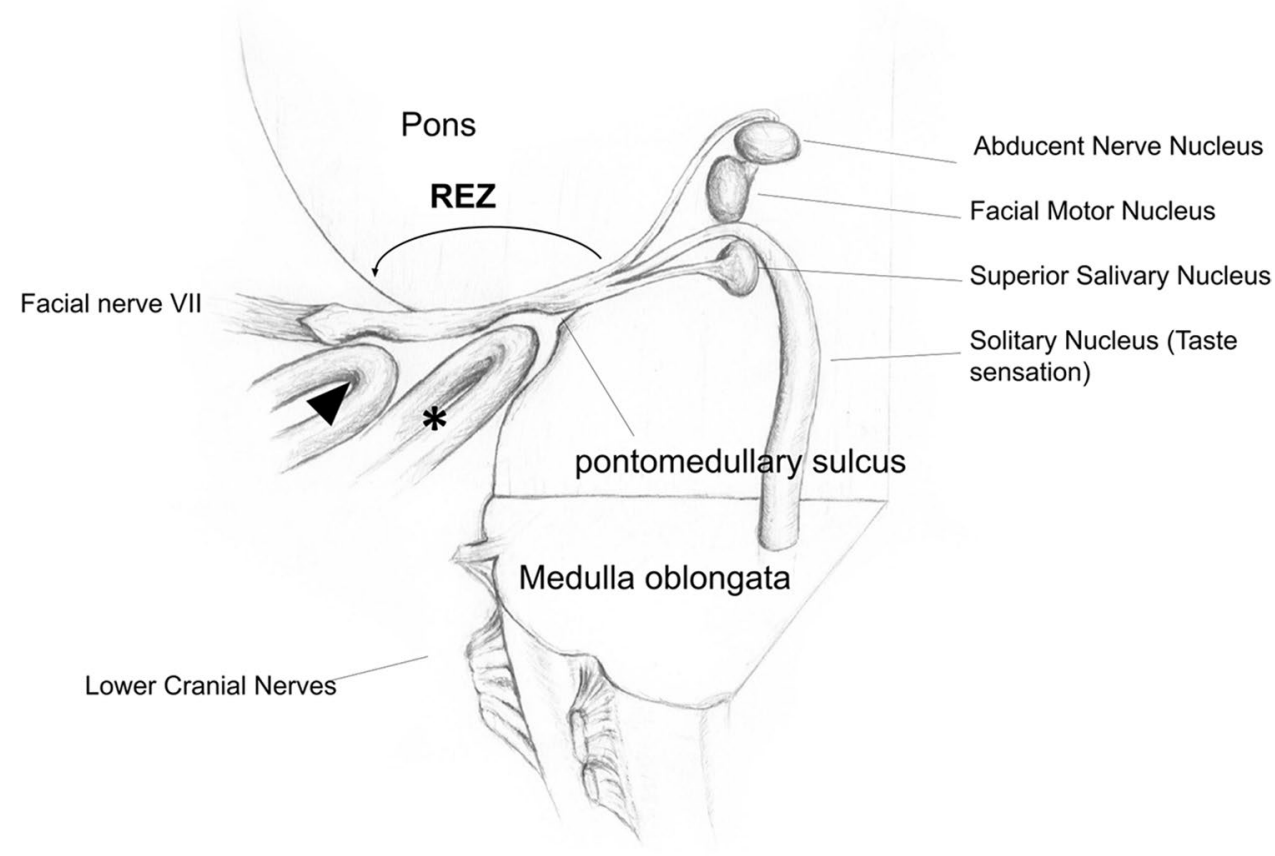


Fig. 2 Endoscopic inspection with a $45^{\circ}$ endoscope showing grooving/indentation of the facial nerve. A: proximal grooving at the brainstem (arrows). B: distal grooving where the nerve leaves the brainstem (arrows)
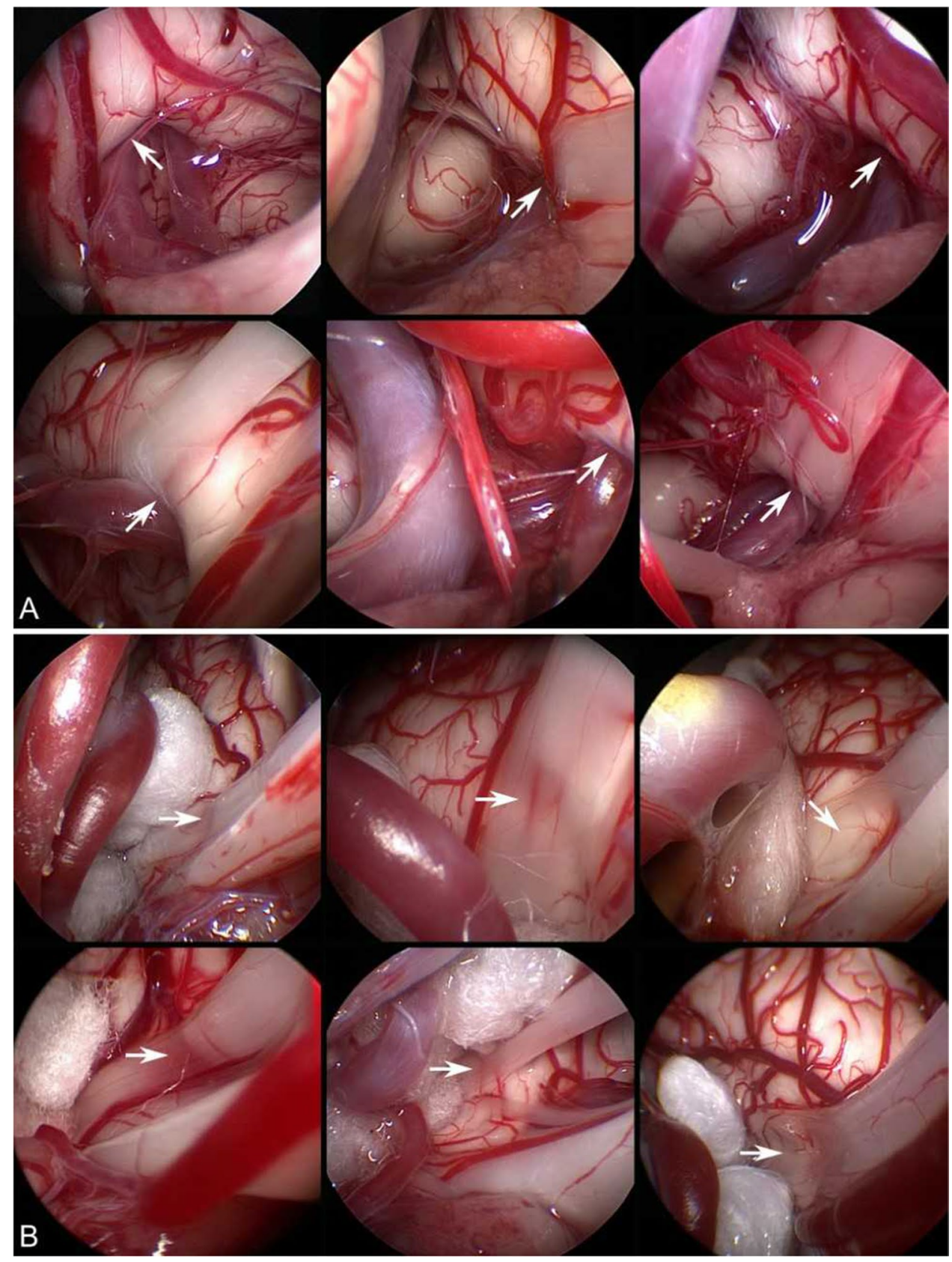

\section{Preoperative imaging}

To identify the cause of HFS, careful analysis of the preoperative MR imaging with constructive interference in steady state (3D CISS) and time of flight (3D TOF) angiography sequences was performed.

\section{Operative technique}

All MVDs were performed by the senior author (HWSS) through a lower retrosigmoid craniotomy in supine position under facial electromyography (EMG) and brainstem auditory evoked potential (BAEP) monitoring. Lateral spread response was recorded routinely. After arachnoid dissection, the facial REZ was visualized with a $45^{\circ}$ endoscope [12]. The course of the facial nerve was inspected. Depending on the anatomical situation, the decompression was done by interposing shredded Teflon or transposing the vessel using a Gortex or Teflon sling and fixing it to the skull base dura [13]. Every attempt was made to leave the original compression zone free of contact to Teflon $[9,11]$. The exact etiology and type of compression as well as visual control of decompression were more precisely determined intraoperatively by endoscopic inspection using a $45^{\circ}$ endoscope 
[12]. Intraoperative determination of facial nerve grooving was noted as well as its position.

\section{Statistical methods}

Analysis was performed using R software version 3.6.3 (R Foundation for Statistical Computing, Vienna, Austria) [40]. Continuous variables were described using mean \pm standard deviation (SD) or median with interquartile range (IQR) according to distribution. Categorical variables were described as counts and percentages. The trend of the postoperative course of recovery was estimated using a generalized additive model of the severity of symptoms over time using ggplot2 package version 3.3.3 [43]. To compare the five groups of postoperative remission patterns, multinomial logistic regression was performed using IBM $®$ SPSS $®$ version 22.0 (IBM Corp., Armonk, NY, USA), for which we reported odds ratio (OR), 95\% confidence intervals $(\mathrm{CI})$ and $P$ values.

Time to final recovery was demonstrated by Kaplan-Meier curves. The difference in time to recovery between different groups was compared using the LogRank test. When pairwise comparisons were done, a Benjamini-Hochberg (BH) adjustment was applied. Two uni- and multivariable Cox regression analyses were performed to identify independent factors affecting time to final recovery with reporting of hazard ratios (HR), 95\% CI and $P$ values. Survival analysis was performed using the survival package version 3.2-7 [40]. For all regression analyses: all a priori selected predictors were entered in multivariable analysis regardless of their significance on the univariable level, and stepwise backward elimination was used to select the model of best fit. Statistical significance was set at a $P$ value of $<0.05$ (two-tailed).

\section{Results}

\section{Study population and overall recovery}

A total of 379 patients underwent a total of 416 operations. Thirty-seven data entries for the second or third operation for the same patient were excluded from our analysis. Follow-up data could not be obtained in 7 patients. Ten patients had a follow-up $<6$ months, and 9 patients were reoperated within the first 6 months following the first operation. Four patients had intraoperatively no evident arterial compression of the nerve (1 venous compression, 2 arachnoid band strictures and 1 patient with no compression who had synkinesis after facial palsy, but no hemifacial spasm). Finally, 349 data entries of de-novo MVD were included. The mean (SD) follow-up was 54.6 (35.9) months.
A total of 323 patients $(92.6 \%)$ had a satisfactory outcome with at least $90 \%$ resolution of the symptoms, while 308 patients (88.3\%) showed at some point $100 \%$ complete resolution of the symptoms along the postoperative course; $269(77.1 \%)$ patients had complete resolution of the symptoms at the last follow-up. Only 3 patients $(0.9 \%)$ showed no improvement at all after surgery. General characteristics of the study population and the follow-up period are tabulated in Table 1. A total of 246 patients $(70.5 \%)$ showed significant intraoperative arterial compressions without grooving of the nerve, while 103 patients had visible indentation/ grooving of the nerve at the site of compression; 52 patients (14.9\%) with proximal grooving (Fig. 2A) and 51 patients (14.6\%) with distal grooving (Fig. 2B). Postoperative facial nerve weakness occurred in 32 cases $(9.2 \%)$. Six patients (1.7\%) out of these had an immediate facial nerve weakness, while 26 patients (7.4\%) experienced a delayed facial nerve weakness occurring usually 10 days after surgery.

\section{General trend of recovery and different patterns within the study population}

The overall postoperative recovery of all patients was plotted against time as illustrated in Fig. 3. A steep remission is witnessed within the first 6 months after surgery followed by a relapse peaking at $\sim 8$ months with a second improvement at 13-16 months after surgery; $90.2 \%$ of the patients who demonstrated postoperative complete resolution of the symptoms reported it within 16 months after surgery, and $88 \%$ of them experienced full resolution within 12 months. We identified 5 main clinical patterns (Fig. 4 and Table 1):

Group 1: Immediate full resolution 129/349 (36.96\%)

Group 2: Gradual full resolution 86/349 (24.64\%)

Group 3: Initial full resolution with relapse(s) and final resolution "Eventual Resolution" 54/349 (15.47\%)

Group 4: Initial full resolution with relapse(s) without final resolution 39/349 (11.17\%)

Group 5: Improvement without full resolution at any point $41 / 349(11.75 \%)$

Resolution is defined as $100 \%$ disappearance of the symptoms. Despite residual symptoms in groups 4 and 5 , $54 / 80$ patients $(67.5 \%)$ had $>90 \%$ improvement at the last follow-up.

On the univariable level, patients with anterior inferior cerebellar artery AICA (OR: 0.37; CI 0.17-0.79), or AICA/vertebral artery (VA) compression (OR: 0.34; CI $0.13-0.90)$, as well as patients who developed postoperative facial palsy (OR: 0.2; CI 0.06-0.69) had lower odds of having a delayed (group 2) versus immediate resolution (group 1). Male patients (OR: 0.26; CI 0.12-0.53), 
Table 1 Summary of predictor risk factors by improvement pattern

\begin{tabular}{|c|c|c|c|c|c|c|c|}
\hline $\begin{array}{l}\text { Dependent: Improvement } \\
\text { pattern }\end{array}$ & & $\begin{array}{l}\text { Group } 1 \text { (Imme- } \\
\text { diate Resolu- } \\
\text { tion) }\end{array}$ & $\begin{array}{l}\text { Group } 2 \\
\text { (Gradual } \\
\text { Resolution) }\end{array}$ & $\begin{array}{l}\text { Group } 3 \\
\text { (Eventual } \\
\text { Resolution) }\end{array}$ & $\begin{array}{l}\text { Group } 4 \\
\text { (Eventual } \\
\text { Relapse) }\end{array}$ & $\begin{array}{l}\text { Group } 5 \text { (No } \\
\text { full Resolu- } \\
\text { tion) }\end{array}$ & Total \\
\hline Total N (\%) & & $129(37.0)$ & $86(24.6)$ & $54(15.5)$ & $39(11.2)$ & $41(11.7)$ & 349 \\
\hline Follow up (months) & Mean (SD) & $51.2(35.9)$ & $62.5(33.7)$ & $68.7(35.4)$ & $54.9(35.3)$ & $30.2(28.8)$ & $54.6(35.9)$ \\
\hline Age (years) & Mean (SD) & $56.1(12.3)$ & $53.5(11.4)$ & $55.8(12.7)$ & $55.6(11.3)$ & $54.1(12.3)$ & $55.1(12.1)$ \\
\hline \multirow[t]{2}{*}{ Sex } & Female & $61(47.3)$ & $47(54.7)$ & $42(77.8)$ & $30(76.9)$ & $29(70.7)$ & 209 (59.9) \\
\hline & Male & $68(52.7)$ & $39(45.3)$ & $12(22.2)$ & $9(23.1)$ & $12(29.3)$ & $140(40.1)$ \\
\hline Symptom Duration (years) & Median (IQR) & $6.0(7.0)$ & $7.0(6.0)$ & $5.0(4.8)$ & $8.0(6.0)$ & $7.0(5.0)$ & $7.0(6.0)$ \\
\hline \multirow[t]{2}{*}{ Side } & Left & $80(62.0)$ & $50(58.1)$ & $27(50.0)$ & $29(74.4)$ & $22(53.7)$ & $208(59.6)$ \\
\hline & Right & $49(38.0)$ & $36(41.9)$ & $27(50.0)$ & $10(25.6)$ & $19(46.3)$ & $141(40.4)$ \\
\hline \multirow[t]{7}{*}{ Etiology } & PICA & $38(29.5)$ & $41(47.7)$ & $15(27.8)$ & $13(33.3)$ & $15(36.6)$ & $122(35.0)$ \\
\hline & AICA & $35(27.1)$ & $14(16.3)$ & $16(29.6)$ & $17(43.6)$ & $10(24.4)$ & $92(26.4)$ \\
\hline & AICA PICA & $11(8.5)$ & $8(9.3)$ & $5(9.3)$ & $2(5.1)$ & $4(9.8)$ & $30(8.6)$ \\
\hline & AICA PICA VA & $8(6.2)$ & $4(4.7)$ & $0(0.0)$ & $0(0.0)$ & $1(2.4)$ & $13(3.7)$ \\
\hline & AICA VA & $19(14.7)$ & $7(8.1)$ & $9(16.7)$ & $3(7.7)$ & $3(7.3)$ & $41(11.7)$ \\
\hline & PICA VA & $14(10.9)$ & $9(10.5)$ & $7(13.0)$ & $4(10.3)$ & $4(9.8)$ & $38(10.9)$ \\
\hline & VA & $4(3.1)$ & $3(3.5)$ & $2(3.7)$ & $0(0.0)$ & $4(9.8)$ & $13(3.7)$ \\
\hline \multirow[t]{2}{*}{ Decompression } & Teflon & $119(92.2)$ & $80(93.0)$ & $51(94.4)$ & 35 (89.7) & $38(92.7)$ & 323 (92.6) \\
\hline & Sling & $10(7.8)$ & $6(7.0)$ & $3(5.6)$ & $4(10.3)$ & $3(7.3)$ & $26(7.4)$ \\
\hline \multirow[t]{3}{*}{ Grooving } & No & $96(74.4)$ & $51(59.3)$ & $44(81.5)$ & $32(82.1)$ & $23(56.1)$ & $246(70.5)$ \\
\hline & Brainstem & $20(15.5)$ & $20(23.3)$ & $5(9.3)$ & $3(7.7)$ & $4(9.8)$ & $52(14.9)$ \\
\hline & Peripheral & $13(10.1)$ & $15(17.4)$ & $5(9.3)$ & $4(10.3)$ & $14(34.1)$ & $51(14.6)$ \\
\hline \multirow[t]{2}{*}{ Facial Palsy } & No & $109(84.5)$ & $83(96.5)$ & 48 (88.9) & $36(92.3)$ & $41(100.0)$ & $317(90.8)$ \\
\hline & Yes & $20(15.5)$ & $3(3.5)$ & $6(11.1)$ & $3(7.7)$ & $0(0.0)$ & $32(9.2)$ \\
\hline
\end{tabular}

or patients with a longer symptom duration (OR: 0.92; CI 0.85-0.99) had lower odds of having a relapse before final resolution (group 3) in comparison to immediate resolution (group 1). Male patients also had lower odds of having final residual spasms (group 4) (OR: 0.27; CI 0.12-0.61) versus immediate resolution (group 1). Male gender (OR: 0.37 ; CI $0.17-0.79$ ) had also lower odds of allocation to group 5 in comparison to group 1, while peripheral grooving of the facial nerve (OR: 4.5; CI 1.86-10.85) predicted incomplete resolution of symptoms (group 5) compared to group 1.

In the multivariable analysis, statistically significant independent predictors of allocation to one of the five defined remission patterns were sex, location of vessel induced grooving and postoperative facial palsy. Compared to group 1, male patients were less likely to be allocated to group 3 (OR: 0.25 ; CI $0.12-0.54$ ), group 4 (OR: 0.28 ; CI 0.12-0.65) or group 5 (OR: 0.39; CI 0.18-0.87). Peripheral grooving increased the odds of patient allocation to group 2 (OR: 2.32; Ci 1.01-5.35) or group 5 (OR: 5.32; CI 2.12-13.40), whereas the development of postoperative facial palsy decreased the odds of patient allocation to group 2 (OR: 0.2; CI 0.06-0.7) in comparison to group 1 . The performed technique of decompression (interposition vs. transposition) and the remaining tested factors did not show statistical significance on influencing the pattern of recovery.

\section{Factors affecting time to final recovery}

Eventual complete resolution of symptoms regardless of postoperative course fluctuations was reached in 269 (77.1\%) patients occurring in 50\% at a median of 142 days (4.7 months) (95\%CI 83-300) after surgery. A significant difference in time to final recovery according to sex $(p<0.001)$, development of postoperative facial palsy ( $p=0.047)$ and the location of vessel induced grooving $(p=0.005)$ was shown (Fig. 5). Pairwise comparison showed a significantly shorter time to recovery with proximal nerve grooving (median: 49 days; 95\%CI 5-227) compared to no grooving (median: $122.5 ; 95 \% \mathrm{CI} 63-325 ; p=0.02$ ), and to distal grooving (median: 465 95\%CI 246-2303; $p=0.002$ ). Statistically significant factors affecting time to final recovery are shown in Fig. 5. Results of the multivariable and univariable analysis of risk factors for final recovery for patients with a minimum follow-up of 6 months as well as those with a minimum follow-up of 12 months are tabulated in Table 2. 


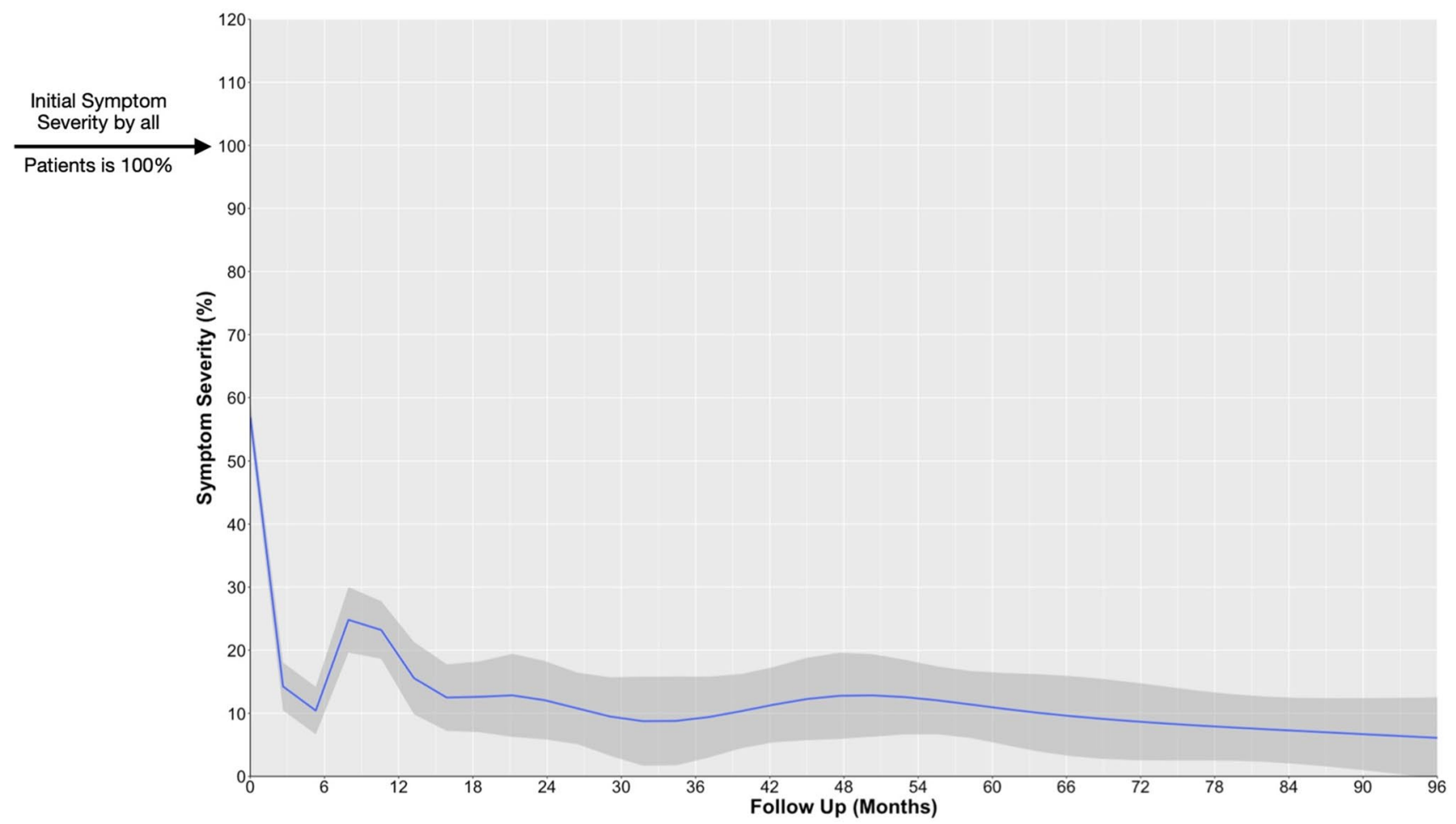

Fig. 3 Overall trend of postoperative symptoms resolution following MVD in HFS in our patients. Initial symptom severity in all patients was $100 \%$. Follow-up beyond 8 years is not depicted on this graph

\section{Discussion}

Several studies investigated the predicting factors influencing the outcome following MVD in HFS patients [6, 17, $18,23,39]$. Fewer studies analyzed the course of symptoms improvement and patterns of recovery following MVD attributing delayed resolution of the spasms to various predicting factors [18, 24, 27, 32, 34]. Our time analysis addressed each patient individually while the trend analysis addressed the different trend groups.

\section{Significance of facial nerve indentation/grooving}

The main distinctive finding of our study is showing that the location of facial nerve grooving is a prognostic factor regarding the outcome. Distal indentation is associated with delayed recovery and poor outcome, while proximal grooving correlates with earlier recovery and better outcomes. Some authors reported that intraoperative evident indentation of the facial nerve is a good prognostic factor for symptom improvement following MVD for HFS [21, 26], while others considered it a poor prognostic factor [20]. However, the exact position of that indentation was not clearly mentioned or identified. Studying the microscopic anatomy of the REZ and proximal part of the facial nerve is pivotal to interpret such differences regarding the outcome.
Firstly, not all fibers leave the brainstem at the same point. In fact, they exit over a segment (REZ). Moreover, the fibers continue to be covered by central myelin till the end of the transitional zone (Redlich-Obersteiner zone) which continues till the proximal part of the nerve root. [5, 31, 41, 44]

Secondly, it is agreed upon that compressions peripheral to the transitional zone of myelin and covered only by peripheral myelin are usually insignificant $[8,14]$. However, it is also important to note that the transition zone length between central and peripheral myelin is variable among the different patients [27, 30].

We identified indentation of the nerve in 103 patients (52 proximal and 51 distal). Our analysis of time needed until recovery showed strong statistical significance. On one hand, proximal indentation is associated with earlier final recovery, and on the other hand, distal indentation was a strong predictor for failure of complete resolution (group 5) and longer time for recovery.

Delayed cure seems logical if considering that primary HFS is due to hyperactivity in facial nerve due to chronic irritation caused by the vascular compression. The significant difference in outcome between proximal and distal grooving may be attributed to the sudden alleviation of the facial nerve nucleus irritation following proximal decompression or due to the complexity of the regeneration process at the distal transitional zone between central and peripheral 

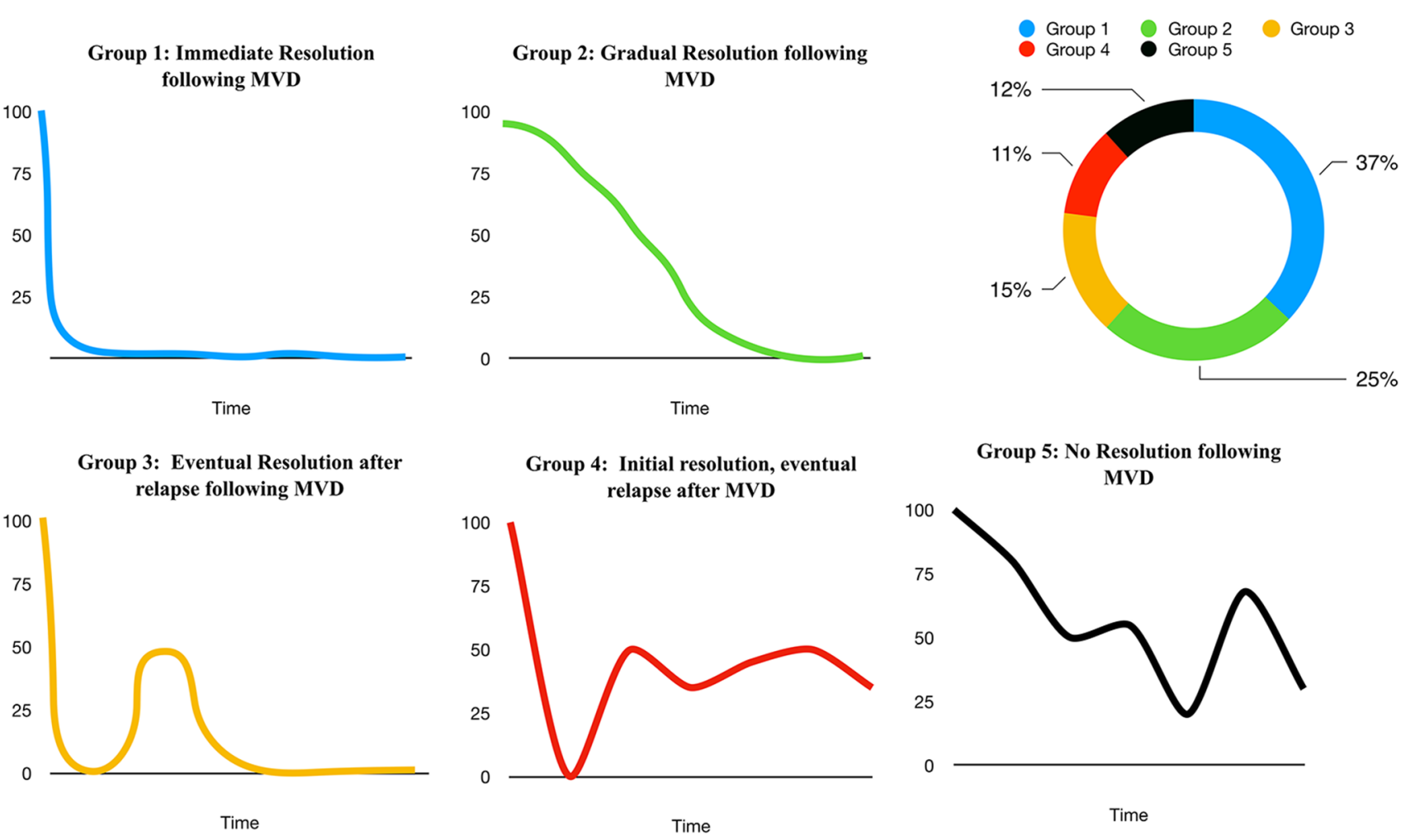

Fig. 4 Illustration sketch of the different patterns of symptoms resolution following MVD in HFS. The five groups: Group 1: immediate full resolution, Group 2: gradual full resolution, Group 3: eventual resolution, Group 4: initial full resolution with relapse(s) without

final resolution and Group 5: improvement without full resolution and pie chart showing percentage distribution of each group in our patients

myelin. Our described distal indentation usually took place in the transitional zone, and this might be the reason why recovery takes longer in these patients. More peripherally located compressions beyond the transitional zone in areas solely myelinated with peripheral myelin show high resistance to vascular compressions and usually do not cause HFS. [10, 15, 16]

\section{When to re-operate?}

Some authors reported that failure to improve within the first postoperative week warrants reoperation.[37], Lee et al.[24] suggested that 6 months is the minimum period to wait before deciding for the outcome of the MVD as they showed similar outcomes at 6 and 9 months to the outcomes at 12 months. In our series, a remarkable recovery is also witnessed within the first 6 months (Fig. 3) after surgery, which supports the results of Lee et al.[24] However, a general partial relapse of the symptoms follows around $8^{\text {th }}$ month with secondary remission around 13th month postoperatively. Therefore, monitoring the postoperative course would be helpful as it would reflect the success of the operation largely. A relapse of the symptoms should be met with some patience without rushing directly to reoperation. By failure of considerable improvement within 12 months, reoperation should be considered.

We disagree with authors who suggested that 3 months of follow-up is enough to evaluate the outcome following MVD for HFS [21, 34]. However, we agree with authors who suggested waiting for longer periods of at least 1 year. [24, 33]

\section{Does sex matter?}

Although males and females did not differ regarding the overall final outcome, gender showed surprisingly significant difference regarding the pattern and time course of recovery. Males are more likely to show earlier improvement and less likely to develop relapses. Most of the previous studies and reports including our own previous studies did not show significant difference regarding sex on the final outcome. [28, 41] However, in few studies males' privilege was reported regarding long-term success and lower recurrence rates following MVD in comparison to females. [3, 4] We cannot explicitly explain these results. However, this might be related to the partial subjectivity of the assessment as outcomes depend also on the patient's self-assessment of improvement and some studies reported differences between males and females regarding describing and reporting 


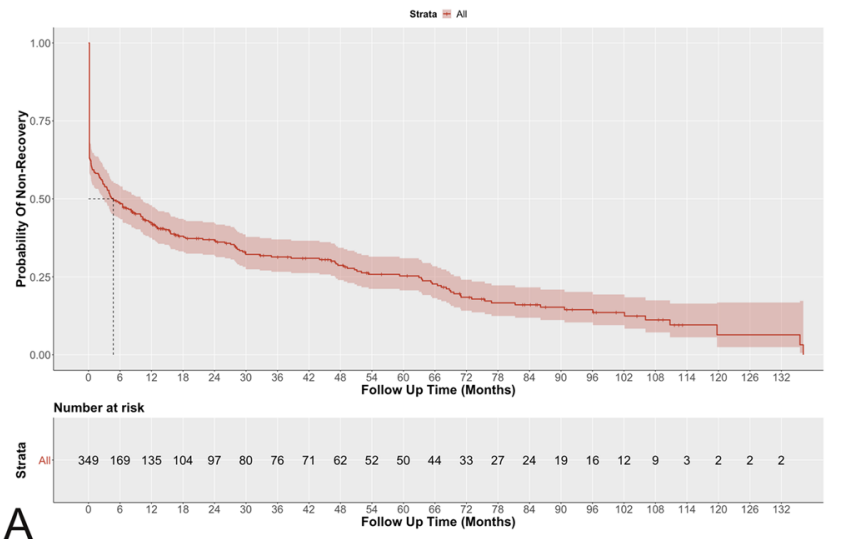

A

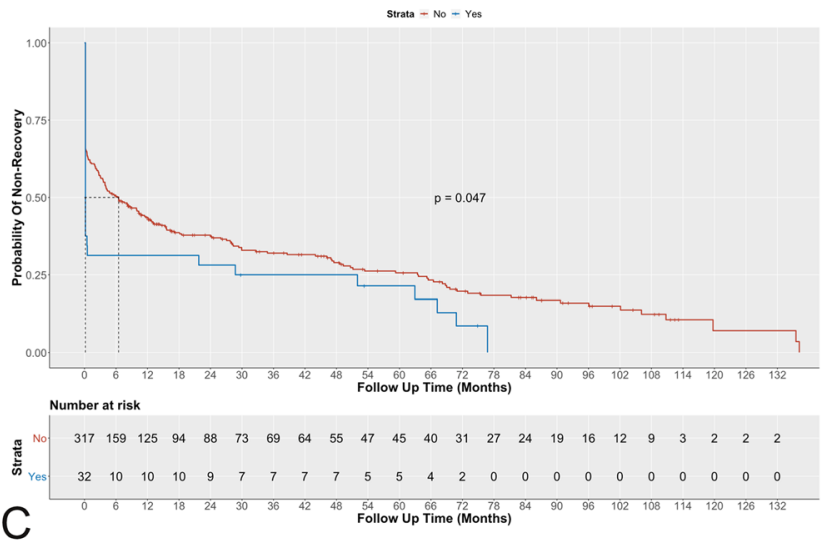

C

\begin{tabular}{|c|c|c|c|c|c|}
\hline \multicolumn{2}{|l|}{ Variable } & \multirow{2}{*}{\begin{tabular}{l|l}
$\mathbf{N}$ & $\mathbf{1}$ \\
226 &
\end{tabular}} & \multirow{2}{*}{$\begin{array}{c}\text { Hazard ratio } \\
\end{array}$} & \multicolumn{2}{|r|}{$\mathbf{p}$} \\
\hline \multirow[t]{2}{*}{ Age } & $>50$ & & & Reference & \\
\hline & $\leq 50$ & 123 & $\rightarrow$ & $0.79(0.59,1.06)$ & 0.12 \\
\hline \multirow[t]{2}{*}{ Sex } & Female & 209 & 中 & Reference & \\
\hline & Male & 140 & $1+$ & $1.61(1.22,2.13)<$ & 0.001 \\
\hline \multicolumn{2}{|c|}{ SymptomDuration $\geq 6$} & 204 & 口 & Reference & \\
\hline & $<6$ & 145 & $=-1$ & $1.36(1.03,1.80)$ & 0.03 \\
\hline \multirow[t]{3}{*}{ Grooving } & No & 246 & $\mathbf{\square}$ & Reference & \\
\hline & Brainstem & 52 & $\because$ & $1.48(1.01,2.17)$ & 0.04 \\
\hline & Peripheral & 51 & 1 & $0.72(0.48,1.07)$ & 0.11 \\
\hline \multirow[t]{2}{*}{ FacialPalsy } & No & 317 & $\square$ & Reference & \\
\hline & Yes & 32 & $=$ & $1.44(0.91,2.28)$ & 0.12 \\
\hline
\end{tabular}

Fig. 5 Kaplan-Meier curves illustrate time to final resolution of the spasms following MVD for all patients and after stratification according to individual significant variables with comparison of the strata using the log rank test. A: for all patients without comparing any factors, B: sex (males and females), C: facial palsy yes/no, D: presence/

symptoms in general. In such studies, it has been stated that females are more likely to describe symptoms more often and precisely than men. This might explain why women reported more relapses and delayed recoveries in comparison to men despite the fact that the final outcome did not differ significantly. [1, 22, 38] Therefore, we recommend in the near future developing new more objective tools to assess spasm-intensity and frequency.
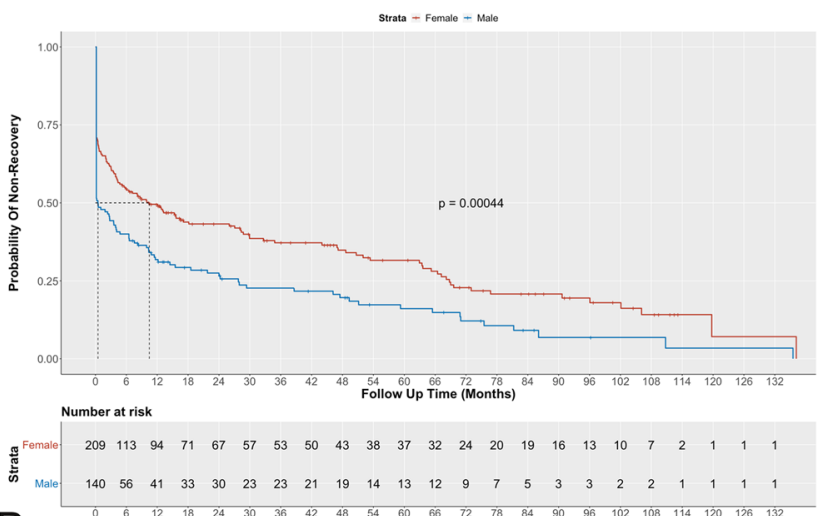

B

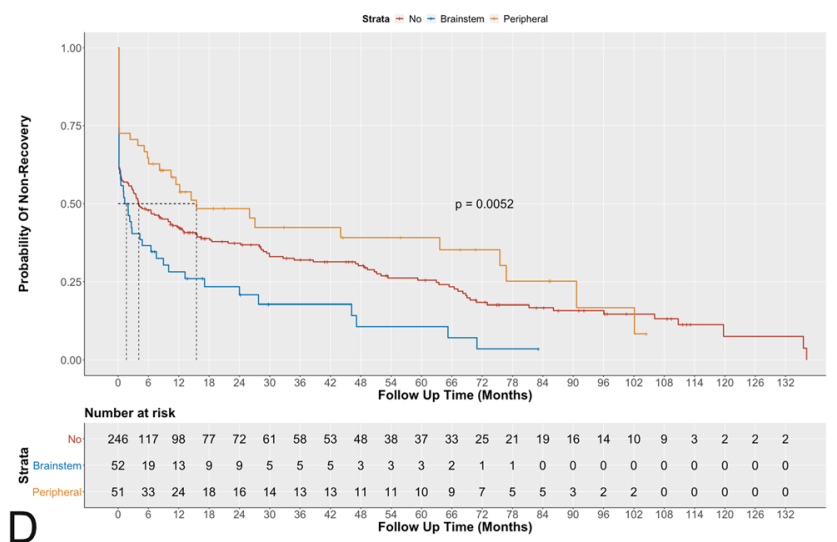

D 54
Follow Up U Time (Months) absence of indentation/grooving of the nerve and its location and E: Forrest plot for independent factors affecting time to final recovery showing significance of sex, disease duration and location of the facial nerve grooving

\section{Significance of the compressing vessel}

Compressions caused by AICA and complex compression with AICA and VA were associated with immediate resolution rather than a delayed recovery. Some authors showed similar results to our results, while other authors declared also better outcomes in cases of compressions caused by PICA rather than other vessels $[27,30]$. 
Table 2 Multivariable and Univariable Analysis of Risk Factors for Final Recovery

\begin{tabular}{|c|c|c|c|c|c|c|c|}
\hline \multirow[b]{2}{*}{$\begin{array}{l}\text { Dependent: Final } \\
\text { Recovery }\end{array}$} & & \multicolumn{3}{|c|}{ Follow up $\geq 6$ months } & \multicolumn{3}{|c|}{ Follow up $\geq 1$ year } \\
\hline & & all & HR (univariable) & $\begin{array}{l}\text { HR (multivariable } \\
\text { reduced) }{ }^{\mathrm{b}}\end{array}$ & all & HR (univariable) & $\begin{array}{l}\text { HR (multivariable } \\
\text { reduced) }\end{array}$ \\
\hline \multirow[t]{2}{*}{ Age (years) } & $>50$ & $226(64.8)$ & - & - & $206(64.6)$ & - & - \\
\hline & $\leq 50$ & $123(35.2)$ & $\begin{array}{c}0.86(0.65-1.14 \\
p=0.308)\end{array}$ & $\begin{array}{l}0.79(0.59-1.06, \\
p=0.116)\end{array}$ & $113(35.4)$ & $\begin{array}{c}0.87(0.66-1.17 \\
p=0.363)\end{array}$ & $\begin{array}{l}0.80(0.59-1.08 \\
p=0.151)\end{array}$ \\
\hline \multirow[t]{2}{*}{ Sex } & Female & 209 (59.9) & - & - & $190(59.6)$ & - & - \\
\hline & Male & $140(40.1)$ & $\begin{array}{c}1.61(1.23-2.11 \\
\boldsymbol{p}<\mathbf{0 . 0 0 1})\end{array}$ & $\begin{array}{l}1.61(1.22-2.13, \\
p=0.001)\end{array}$ & $129(40.4)$ & $\begin{array}{c}1.65(1.25-2.17, \\
p<\mathbf{0 . 0 0 1})\end{array}$ & $\begin{array}{l}1.63(1.22-2.17 \\
p=0.001)\end{array}$ \\
\hline \multirow{2}{*}{$\begin{array}{l}\text { Symptom Dura- } \\
\text { tion (years) }\end{array}$} & $\geq 6$ & $204(58.5)$ & - & - & $184(57.7)$ & - & - \\
\hline & $<6$ & $145(41.5)$ & $\begin{array}{c}1.26(0.97-1.65 \\
p=0.086)\end{array}$ & $\begin{array}{l}1.36 \\
p=\mathbf{0 . 0 2 8})\end{array}$ & $135(42.3)$ & $\begin{array}{c}1.26(0.95-1.66 \\
p=0.105)\end{array}$ & $\begin{array}{l}1.35 \\
p=\mathbf{0 . 0 3 8})\end{array}$ \\
\hline \multirow[t]{2}{*}{ Side } & Left & $208(59.6)$ & - & - & $191(59.9)$ & - & - \\
\hline & Right & $141(40.4)$ & $\begin{array}{c}0.98(0.75-1.29 \\
p=0.906)\end{array}$ & - & $128(40.1)$ & $\begin{array}{c}0.94(0.71-1.24 \\
p=0.642)\end{array}$ & - \\
\hline \multirow[t]{7}{*}{ Etiology } & PICA & $122(35.0)$ & - & - & $114(35.7)$ & - & - \\
\hline & AICA & $92(26.4)$ & $\begin{array}{c}0.92(0.65-1.30 \\
p=0.632)\end{array}$ & - & $84(26.3)$ & $\begin{array}{c}0.93(0.65-1.33 \\
p=0.687)\end{array}$ & - \\
\hline & AICA PICA & $30(8.6)$ & $\begin{array}{c}1.57(0.93-2.64 \\
p=0.090)\end{array}$ & - & $24(7.5)$ & $\begin{array}{c}1.83(1.05-3.19, \\
p=0.034)\end{array}$ & - \\
\hline & AICA PICA VA & $13(3.7)$ & $\begin{array}{c}1.93(0.95-3.91, \\
p=0.067)\end{array}$ & - & $12(3.8)$ & $\begin{array}{c}1.87(0.90-3.88 \\
p=0.094)\end{array}$ & - \\
\hline & AICA VA & $41(11.7)$ & $\begin{array}{c}1.18(0.77-1.81 \\
p=0.455)\end{array}$ & - & $39(12.2)$ & $\begin{array}{c}1.16(0.75-1.80 \\
p=0.512)\end{array}$ & - \\
\hline & PICA VA & $38(10.9)$ & $\begin{array}{c}1.25(0.79-1.98 \\
p=0.337)\end{array}$ & - & $35(11.0)$ & $\begin{array}{c}1.42(0.89-2.27 \\
p=0.139)\end{array}$ & - \\
\hline & VA & $13(3.7)$ & $\begin{array}{c}0.86(0.41-1.80 \\
p=0.686)\end{array}$ & - & $11(3.4)$ & $\begin{array}{c}0.88(0.40-1.92 \\
p=0.741)\end{array}$ & - \\
\hline \multirow[t]{2}{*}{ Decompression } & Teflon & 323 (92.6) & - & - & $296(92.8)$ & - & - \\
\hline & Sling & $26(7.4)$ & $\begin{array}{c}0.79(0.47-1.30 \\
p=0.349)\end{array}$ & - & $23(7.2)$ & $\begin{array}{c}0.75(0.44-1.27 \\
p=0.285)\end{array}$ & - \\
\hline \multirow[t]{3}{*}{ Grooving } & No & $246(70.5)$ & - & - & $228(71.5)$ & - & - \\
\hline & Brainstem & $52(14.9)$ & $\begin{array}{c}1.63(1.12-2.39 \\
\boldsymbol{p}=\mathbf{0 . 0 1 1})\end{array}$ & $\begin{array}{l}1.48(1.01-2.17, \\
p=\mathbf{0 . 0 4 4})\end{array}$ & $46(14.4)$ & $\begin{array}{c}1.65(1.11-2.45 \\
p=\mathbf{0 . 0 1 3})\end{array}$ & $\begin{array}{l}1.48(1.00-2.21, \\
p=0.052)\end{array}$ \\
\hline & Peripheral & $51(14.6)$ & $\begin{array}{l}0.73(0.49-1.09 \\
\mathrm{p}=0.129)\end{array}$ & $\begin{array}{l}0.72(0.48-1.07, \\
p=0.105)\end{array}$ & $45(14.1)$ & $\begin{array}{l}0.77(0.51-1.17 \\
\mathrm{p}=0.217)\end{array}$ & $\begin{array}{l}0.75(0.50-1.14 \\
p=0.180)\end{array}$ \\
\hline \multirow[t]{2}{*}{ Facial Palsy } & No & $317(90.8)$ & - & - & $287(90.0)$ & - & - \\
\hline & Yes & $32(9.2)$ & $\begin{array}{c}1.56(1.00-2.43 \\
p=\mathbf{0 . 0 4 8})\end{array}$ & $\begin{array}{l}1.44(0.91-2.28, \\
p=0.122)\end{array}$ & $32(10.0)$ & $\begin{array}{c}1.58(1.01-2.46 \\
\boldsymbol{p}=\mathbf{0 . 0 4 5})\end{array}$ & $\begin{array}{l}1.45(0.91-2.31, \\
p=0.115)\end{array}$ \\
\hline
\end{tabular}

${ }^{\mathrm{b}}$ Number in dataframe $=349$, Number in $\operatorname{model}=349$, Missing $=0$, Number of events $=269$, Concordance $=0.619 \quad(\mathrm{SE}=0.022)$, R-squared $=0.080$ ( Max possible $=0.993)$, Likelihood ratio test $=29.252(\mathrm{df}=6, p=0.000)$

${ }^{a}$ Number in dataframe $=319$, Number in model $=319$, Missing $=0$, Number of events $=251$, Concordance $=0.617 \quad(\mathrm{SE}=0.022)$, $\mathrm{R}$-squared $=0.081($ Max possible $=0.993)$, Likelihood ratio test $=27.016(\mathrm{df}=6, p=0.000)$

\section{Duration of the disease and postoperative course}

Longer disease durations have been usually related to poor outcomes [27, 30]. In our study, shorter disease history less than 6 years was associated with earlier final recovery, but it is not significant on the long-term results. Obviously, prolonged compression might contribute to more structural changes of the nerve and so more time for regeneration.

\section{Facial palsy: friend or enemy?}

Delayed facial nerve weakness should be distinguished from the immediate postoperative weakness. In our study, we had 32 patients $(9.2 \%)$ with postoperative facial palsy. 6 of whom $(1.7 \%)$ had an immediate postoperative facial nerve weakness which we relate to intraoperative manipulations. The other 26 patients experienced a delayed weakness in 
which the exact etiology is still unclear. Interestingly, some studies showed that postoperative delayed facial nerve palsy following MVD is significantly associated with a more favorable outcome after MVD for HFS in both the short and long terms [24, 25]. Our results support this. However, we still consider it also a complication despite its good prognostic value.

\section{Limitations}

We excluded patients with only venous and/or arachnoid band compression, which might also play a role influencing the postoperative recovery. In our series, we had only one patient with pure venous compression who is completely spasm-free immediately after the surgery. Some studies highlighted that arachnoid bands and venous compressions, although rare, may correlate with bad outcomes [14, 30, 42].

\section{Conclusion}

We advise to wait at least 12 months before assessing the outcome of MVD in HFS. Proximal indentation of the facial nerve at the REZ as well as postoperative facial palsy is associated with earlier recovery. On the other hand, distal indentation is associated with relatively worse outcome and longer time for recovery.

Author contribution Conception and design: HWSS and AAM. Acquisition of data: AAM, MM and EER. Analysis and interpretation of data: AAM, RE, MV, MM and AAS. Drafting the article: AAM and HWSS. Critically revising the article: HWSS, EER and AAM. Reviewed submitted version of manuscript: HWSS, EER, AAM, SF, JB, RE, MV and SL. Approved the final version of the manuscript on behalf of all authors: AAM. Statistical analysis: AAM, RE, MV and AAS. Administrative/ technical/material support: MM, RE and SL. Study supervision: HWSS and EER

Funding Open Access funding enabled and organized by Projekt DEAL. This study was completely self-funded by the University Medicine Greifswald, and the authors do not have any other funding source to declare.

\section{Declarations}

Ethics approval All procedures performed in this study involving human participants were in accordance with the ethical standards of the local institutional research committee (Ethical committee of the University Medicine Greifswald) and with the 1964 Helsinki declaration and its later amendments or comparable ethical standards. Ethical committee approval number BB 101/16.

Consent for publication Although no data in this study could lead to public identification of the patients, all the participating patients signed written consents agreeing with publication of their data.
Competing interests The authors declare no competing interests. We have only to mention that Henry W. S. Schroeder was a consultant to Karl Storz SE \& Co. KG, Tuttlingen, Germany.

Open Access This article is licensed under a Creative Commons Attribution 4.0 International License, which permits use, sharing, adaptation, distribution and reproduction in any medium or format, as long as you give appropriate credit to the original author(s) and the source, provide a link to the Creative Commons licence, and indicate if changes were made. The images or other third party material in this article are included in the article's Creative Commons licence, unless indicated otherwise in a credit line to the material. If material is not included in the article's Creative Commons licence and your intended use is not permitted by statutory regulation or exceeds the permitted use, you will need to obtain permission directly from the copyright holder. To view a copy of this licence, visit http://creativecommons.org/licenses/by/4.0/.

\section{References}

1. Abdul-Wahab SA (2011) Sick building syndrome: in Public buildings and workplaces. Springer Science \& Business Media

2. Baldauf J, Rosenstengel C, Schroeder HWS (2019) Nerve compression syndromes in the posterior cranial fossa. Deutsches Aerzteblatt Online. https://doi.org/10.3238/arztebl.2019.0054

3. Barker FG 2nd, Jannetta PJ, Bissonette DJ, Larkins MV, Jho HD (1996) The long-term outcome of microvascular decompression for trigeminal neuralgia. N Engl J Med 334(17):1077-1083

4. Barker FG, Jannetta PJ, Bissonette DJ, Shields PT, Larkins MV, Jho HD (1995) Microvascular decompression for hemifacial spasm. J Neurosurg 82(2):201-210

5. Campos-Benitez M, Kaufmann AM (2008) Neurovascular compression findings in hemifacial spasm. J Neurosurg 109(3):416-420

6. Chang WS, Chung JC, Kim JP, Chung SS, Chang JW (2012) Delayed recurrence of hemifacial spasm after successful microvascular decompression: follow-up results at least 5 years after surgery. Acta Neurochir 154(9):1613-1619

7. Chung SS, Chang JW, Kim SH, Chang JH, Park YG, Kim DI (2000) Microvascular decompression of the facial nerve for the treatment of hemifacial spasm: preoperative magnetic resonance imaging related to clinical outcomes. Acta Neurochir 142(8):901 (6 discussion 907)

8. Collins GS, Reitsma JB, Altman DG, Moons KGM (2015) Transparent Reporting of a multivariable prediction model for Individual Prognosis Or Diagnosis (TRIPOD): the TRIPOD Statement. Br J Surg 102(3):148-158

9. Damaty AE, El Damaty A, Rosenstengel C, Matthes M, Baldauf J, Schroeder HWS (2016) The value of lateral spread response monitoring in predicting the clinical outcome after microvascular decompression in hemifacial spasm: a prospective study on 100 patients. Neurosurg Rev 39(3):455-466

10. De Ridder D, Møller A, Verlooy J, Cornelissen M, De Ridder $\mathrm{L}$ (2002) Is the root entry/exit zone important in microvascular compression syndromes? Neurosurgery 51(2):427-33 (discussion 433-4)

11. El Damaty A, Rosenstengel C, Matthes M, Baldauf J, Dziemba O, Hosemann W, Schroeder HWS (2017) A new score to predict the risk of hearing impairment after microvascular decompression for hemifacial spasm. Neurosurgery 81(5):834-843

12. El Refaee E, Langner S, Baldauf J, Matthes M, Kirsch M, Schroeder HWS (2013) Value of 3-dimensional high-resolution magnetic resonance imaging in detecting the offending vessel in 
hemifacial spasm: comparison with intraoperative high definition endoscopic visualization. Neurosurgery 73(1):58-67 (discussion 67)

13. El Refaee E, Langner S, Marx S, Rosenstengel C, Baldauf J, Schroeder HWS (2019) Endoscope-assisted microvascular decompression for the management of hemifacial spasm caused by vertebrobasilar dolichoectasia. World Neurosurg 121:e566-e575

14. El Refaee E, Marx S, Rosenstengel C, Baldauf J, Schroeder HWS (2020) Arachnoid bands and venous compression as rare causes of hemifacial spasm: analysis of etiology in 353 patients. Acta Neurochir 162(1):211-219

15. Fleming GWTH, Fleming GWT (1938) Structure of the nerve root. I. Nature of the junction between the central and the peripheral nervous system. (Arch. Neur. and Psychiat., vol. xxxvii, p. 555, March, 1937.) Tarlov, I. M. J Ment Sci 84(48):225-225

16. Guclu B, Sindou M, Meyronet D, Streichenberger N, Simon E, Mertens P (2011) Cranial nerve vascular compression syndromes of the trigeminal, facial and vago-glossopharyngeal nerves: comparative anatomical study of the central myelin portion and transitional zone; correlations with incidences of corresponding hyperactive dysfunctional syndromes. Acta Neurochir 153(12):2365-2375

17. Jin Y, Zhao C, Su S, Zhang X, Qiu Y, Jiang J (2015) Residual hemifacial spasm after microvascular decompression: prognostic factors with emphasis on preoperative psychological state. Neurosurg Rev 38(3):567-72 (discussion 572)

18. Jo KW, Kong DS, Park K (2013) Microvascular decompression for hemifacial spasm: long-term outcome and prognostic factors, with emphasis on delayed cure. Neurosurg Rev 36(2):297-301 (discussion 301-2)

19. Kim YG, Chang WS, Jung HH, Chang JW (2019) The long-term effects of microvascular decompression on social phobia and health-related quality of life in patients with hemifacial spasm: a 3-year prospective study. Acta Neurochir 161(10):2035-2042

20. Kim JP, Chung JC, Chang WS, Chung SS, Chang JW (2012) Outcomes of surgical treatment for hemifacial spasm associated with the vertebral artery: severity of compression, indentation, and color change. Acta Neurochir 154(3):501-508

21. Kim HR, Rhee D-J, Kong D-S, Park K (2009) Prognostic factors of hemifacial spasm after microvascular decompression. J Korean Neurosurg Soc 45(6):336-340

22. Ladwig KH, Marten-Mittag B, Formanek B, Dammann G (2000) Gender differences of symptom reporting and medical health care utilization in the German population. Eur J Epidemiol 16(6):511-518

23. Lee J-A, Kim K-H, Kong D-S, Lee S, Park S-K, Park K (2019) Algorithm to predict the outcome of microvascular decompression for hemifacial spasm: a data-mining analysis using a decision tree. World Neurosurg 125:e797-e806

24. Lee J-A, Park K (2019) Short-term versus long-term outcomes of microvascular decompression for hemifacial spasm. Acta Neurochir 161(10):2027-2033

25. Lee JM, Park HR, Choi YD, Kim SM, Jeon B, Kim H-J, Kim DG, Paek SH (2018) Delayed facial palsy after microvascular decompression for hemifacial spasm: friend or foe? J Neurosurg 129(2):299-307

26. Li S, Feng B, Xie C, You C, Wei X, Zheng X (2016) Good surgical outcomes of hemifacial spasm patients with obvious facial nerve indentation and color change. World Neurosurg 92:218-222

27. Lu T, Xu Y, Xu W, Dai Y, Liang W, Jin W (2018) A multivariate analysis for delayed healing of facial muscle spasm after microvascular decompression. Pak J Med Sci. https://doi.org/10.12669/ pjms.343.15015
28. Mizobuchi Y, Muramatsu K, Ohtani M, Satomi J, Fushimi K, Matsuda S, Nagahiro S (2017) The current status of microvascular decompression for the treatment of hemifacial spasm in Japan: an analysis of 2907 patients using the Japanese diagnosis procedure combination database. Neurol Med Chir 57(4):184-190

29. Møller AR (1991) The cranial nerve vascular compression syndrome: II. A review of pathophysiology Acta Neurochir 113(1-2):24-30

30. Montava M, Rossi V, CurtoFais CL, Mancini J, Lavieille J-P (2016) Long-term surgical results in microvascular decompression for hemifacial spasm: efficacy, morbidity and quality of life. Acta Otorhinolaryngol Ital 36(3):220-227

31. Nomura K, Ryu H, Ohno K, Sato K (2021) Wide distribution of central myelin segment along the facial nerve might explain hemifacial spasm with distal nerve compression. Clin Anat 34(3):405-410

32. Oh E-T, Kim E, Hyun D-K, Yoon SH, Park H, Park H-C (2008) Time course of symptom disappearance after microvascular decompression for hemifacial spasm. J Korean Neurosurg Soc 44(4):245-248

33. Park K, Hong SH, Hong SD, Cho Y-S, Chung W-H, Ryu NG (2009) Patterns of hearing loss after microvascular decompression for hemifacial spasm. J Neurol Neurosurg Psychiatry 80(10):1165-1167

34. Park JS, Kong DS, Lee JA, Park K (2008) Chronologic analysis of symptomatic change following microvascular decompression for hemifacial spasm: value for predicting midterm outcome. Neurosurg Rev 31(4):413-8 (discussion 418-9)

35. Refaee EE, Rosenstengel C, Baldauf J, Pillich DT, Matthes M, Schroeder HWS (2018) Microvascular decompression for patients with hemifacial spasm associated with common trunk anomaly of the cerebellar arteries - case study and review of literature. Oper Neurosurg (Hagerstown) 14(2):121-127

36. Sindou M, Mercier P (2018) Microvascular decompression for hemifacial spasm: outcome on spasm and complications. A review Neurochirurgie 64(2):106-116

37. Soriano-Baron H, Vales-Hidalgo O, Arvizu-Saldana E, MorenoJimenez S, Revuelta-Gutierrez R (2015) Hemifacial spasm: 20-year surgical experience, lesson learned. Surg Neurol Int $6(1): 83$

38. Stenberg B, Wall S (1995) Why do women report "sick building symptoms" more often than men? Soc Sci Med 40(4):491-502

39. Tandon PN, Ramamurthi R (2012) Textbook of neurosurgery, third edition, three, vol set. Jaypee Brothers Medical Publishers Pvt, Limited

40. Team RC, Others (2010) A language and environment for statistical computing. R Foundation for Statistical Computing, Vienna, Austria. http://www.R-project.org

41. Tomii M, Onoue H, Yasue M, Tokudome S, Abe T (2003) Microscopic measurement of the facial nerve root exit zone from central glial myelin to peripheral Schwann cell myelin. J Neurosurg 99(1):121-124

42. Wang X, Thirumala PD, Shah A, Gardner P, Habeych M, Crammond D, Balzer J, Burkhart L, Horowitz M (2013) The role of vein in microvascular decompression for hemifacial spasm: a clinical analysis of 15 cases. Neurol Res 35(4):389-394

43. Wickham H (2016) Data analysis. In: Wickham H (ed) ggplot2: elegant graphics for data analysis. Springer International Publishing, Cham, pp 189-201

44. Yee G-T, Yoo C-J, Han S-R, Choi C-Y (2014) Microanatomy and histological features of central myelin in the root exit zone of facial nerve. J Korean Neurosurg Soc 55(5):244 


\section{Comments}

It is always fascinating to see how analysis of one's large personal series correlates or differs from previously published results - the correlation usually serves as a confirmation of past experiences, whereas difference is thought to be an indicator of previous publications not catching it right. In this sizeable institutional series of endoscope-assisted microvascular decompressions (MVD) for hemifacial spasm (HFS), the authors defined five distinct timecourses of post-surgical progress, and were able to find an association between earlier symptomatic recovery and more proximal nerve indentation by the offending vessel. In contrast with many other reports, the authors suggest a minimum of 1 year wait before finalizing the MVD outcome as some patients would exhibit delayed improvement and even second remission after a relapse of HFS symptoms. Most centers will consider re-exploration if no improvement was noted within 6 months after surgery or if the symptoms relapsed after initial improvement; based on this study results, such re-exploration may not be needed. It is worth noting that the authors mentioned 37 re-operations among 379 patients - it would be interesting to know when and why these re-operations were performed.

I want to congratulate the authors with a very good overall outcome in their impressive series and encourage them to analyze the same patients again in few years (bringing minimum follow up to 36 months and average - to more than 5 years) to see if the patterns of clinical progress became more uniform and consistent.

Konstantin Slavin,

Chicago, USA

Publisher's note Springer Nature remains neutral with regard to jurisdictional claims in published maps and institutional affiliations. 